Rev. Elet. em Gestão, Educação e Tecnologia Ambiental (e-ISSN: 2236-1170)

\title{
ESTIMATIVA DA VULNERABILIDADE À CONTAMINAÇÃO DOS RECURSOS HÍDRICOS SUBTERRÂNEOS DO MUNICÍPIO DE SANTIAGO-RS
}

\author{
Lueni Gonçalves Terra' ${ }^{1}$ Carlos Alberto Löbler², José Luiz Silvério da Silva ${ }^{3}$ \\ 1Universidade Federal de Santa Maria - UFSM: luehniterra@hotmail.com \\ ${ }^{2}$ Universidade Federal de Santa Maria - UFSM: carloslobler@gmail.com \\ ${ }^{3}$ Universidade Federal de Santa Maria - UFSM: silverioufsm@gmail.com
}

http://dx.doi.org/10.5902/223611707887

\section{RESUMO}

As últimas décadas têm sido marcadas pela preocupação da sociedade com a crescente deterioração dos recursos hídricos subterrâneos. Diante deste cenário, o mapeamento de vulnerabilidade do aquífero tem se apresentado como uma ferramenta eficiente para a gestão desses recursos, apontando o risco de contaminação do aquífero por atividades antrópicas. Nesse sentido delinea-se como objetivo principal do presente trabalho: mapear a vulnerabilidade das águas subterrâneas no município de Santiago-Rio Grande do Sul, sul do Brasil, situado na borda da Bacia do Paraná. Utilizando o método GOD, adaptado para as condições brasileiras. Para tanto se elaborou um banco de dados hidrogeológicos relativos a 29 captações que continham todas as informações necessárias à aplicação do método (Grau de confinamento, Meio Aquífero e Profundidade do nível da água). O produto final é o cartograma da vulnerabilidade da região em estudo, que apontou 22 poços, totalizando aproximadamente $76 \%$ com vulnerabilidade insignificante. $17 \%$ dos poços apresentaram vulnerabilidade baixa, 3,5\% em ambas as classes, média e também na alta.

Palavras-chave: vulnerabilidade, GOD, aquífero, SAG, SASG.

\begin{abstract}
The last few decades have been marked by society's concern with the increasing deterioration of groundwater resources. Given this scenario, the vulnerability mapping of aquifers has emerged as an effective tool for the management of these resources, pointing to the risk of contamination of the aquifer by human activities. Accordingly outlines as main objective of this work: mapping the vulnerability of groundwater in the municipality of Santiago Rio Grande do Sul state, southern Brazil, border of Paraná Basin using the GOD method, adapted to Brazilian conditions. Therefore we prepared a database with 29 for hydrogeological catchments containing all information necessary for the method (Degree of confinement, Middle Aquifer depth and water level). The final product is a map of the vulnerability of the region under study, which identified 22 wells, totaling approximately $76.0 \%$, with negligible vulnerability, $17.0 \%$ showed vulnerability low, and medium and high classes presented 3.5\% every one.
\end{abstract}

Key-words: vulnerability, GOD, aquifer, GAS, SGAS. 
Rev. Elet. em Gestão, Educação e Tecnologia Ambiental (e-ISSN: 2236-1170)

\section{INTRODUÇÃO}

Em termos percentuais, Maciel Filho e Nummer (2011) destacam que, aproximadamente $97 \%$ da água estão nos oceanos, $2 \%$ encontra-se congelada nas geleiras e apenas $1 \%$ encontra-se como água superficial e subterrânea. Shiklomanov (1998) aponta que as águas subterrâneas são aproximadamente 100 vezes mais abundantes que as águas superficiais dos rios e lagos. Esses dados nos mostram a importância das águas subterrâneas como reservas de água doce, logo, também de sua proteção.

Água subterrânea é toda a água que ocorre abaixo da superfície da terra, preenchendo os poros ou vazios intergranulares das rochas sedimentares, ou as fraturas, falhas e fissuras das rochas compactas, e que sendo submetida a duas forças (de adesão e de gravidade) desempenha um papel essencial na manutenção da umidade do solo, do fluxo dos rios, lagos e brejos. Borghetti et al. (2004) apontam que as águas subterrâneas cumprem uma importante fase do ciclo hidrológico, uma vez que uma parcela da água da chuva infiltra-se no solo.

A Resolução № 15/2001 define aquífero como "o corpo hidrogeológico com capacidade de acumular e transmitir água através dos seus poros, fissuras ou espaços resultantes da dissolução e carreamento de materiais rochosos". De acordo com a Associação Brasileira de águas subterrâneas (ABAS), os aquíferos podem ser considerados livres ou confinados.

Aquífero livre ou freático é aquele constituído por uma formação geológica permeável e superficial, totalmente aflorante em toda a sua extensão, e limitado na base por uma camada impermeável. A superfície superior da zona saturada está em equilíbrio com a pressão atmosférica. Em aquíferos livres o nível da água varia segundo a quantidade de chuva. São os aquíferos mais comuns e mais explorados pela população. São também os que apresentam maiores problemas de contaminação.

Aquífero confinado ou artesiano é aquele constituído por uma formação geológica permeável, confinada entre duas camadas impermeáveis ou semipermeáveis. A pressão da água no topo da zona saturada é maior do que a pressão atmosférica naquele ponto, o que faz com que a água ascenda no poço para além da zona aquífera. $O$ seu reabastecimento ou recarga, através das chuvas, dá-se preferencialmente nos locais onde a formação aflora à superfície. Neles, o nível da água encontra-se sob pressão, podendo causar artesianismo nos poços que captam suas águas.

A água de aquíferos confinados ou livres pode ser extraída com a perfuração de poços tubulares, que deverão ser bem projetados e construídos, de acordo com as normas da Associação Brasileira de Normas Técnicas (ABNT/NBR 12.212/2006 e ABNT/NBR 12.244/2006), para evitar a contaminação dos meios aquíferos.

Segundo a ABNT/NBR 12.244/2006, "poço é definido como qualquer obra de captação de água subterrânea executada com sonda, mediante perfuração vertical". Essa norma também estabelece que o poço deve ter selo sanitário, perfil construtivo e ser executado por técnicos habilitados.

A vulnerabilidade do aquífero à contaminação é definida como o conjunto de características essenciais dos estratos que separam o aquífero saturado da superfície do solo, determinando sua suscetibilidade a ser atingido por efeitos adversos de uma cargacontaminante aplicada na superfície (FOSTER, 1987). Essa é a grande problemática no que tange a alteração da qualidade das águas subterrâneas, causadas por vazamentos de fossas sépticas, e/ou postos de combustíveis, disposições de resíduos no subsolo não regulamentadas, além de cemitérios e lixões. 
Rev. Elet. em Gestão, Educação e Tecnologia Ambiental (e-ISSN: 2236-1170)

Os aquíferos contaminados possuem altos custos para serem recuperados ou mesmo não possuem métodos eficientes de recuperação, e devido a essa situação, prevenir a contaminação é melhor que remediá-la. Para Foster et al. (2006), "o mapeamento da vulnerabilidade do aquífero à contaminação normalmente é o primeiro passo na avaliação do perigo de contaminação da água subterrânea e na proteção de sua qualidade, em escala municipal ou estadual".

A Constituição Federal (1988) estabelece em seu Art. 26 que a titularidade das águas superficiais e subterrâneas é competência dos estados. O Decreto Estadual nำ42.047/2002 estabelece que a proteção das águas subterrâneas e dos aquíferos no Estado do Rio Grande do Sul compete ao Departamento de Recursos Hídricos (DRH), órgão da Secretaria Estadual do Meio Ambiente (SEMA) o qual é responsável pela outorga.

A Lei Estadual no 11.520/2000, Art. 13, inciso II determina que "a vulnerabilidade dos lençóis d'água subterrâneos será prioritariamente considerada na escolha da melhor alternativa de localização de empreendimentos de qualquer natureza potencialmente poluidores das águas subterrâneas".

Brollo et al.(2000), destacam que a avaliação da vulnerabilidade de aquíferos a contaminação constitui-se em um dos aspectos de maior importância para subsidiar o planejamento de uso do solo bem como para gerenciar a instalação e o funcionamento de empreendimentos potencialmente impactantes aos recursos hídricos subterrâneos.

\section{CARACTERIZAÇÃO DA ÁREA DE ESTUDO}

A cidade de Santiago localiza-se sob as coordenadas geográficas 2911' latitude sul e a 54ํㄴ' longitude oeste de Greenwich, na porção noroeste do Estado do Rio Grande do Sul, como pode ser observado na figura 1. Situada aproximadamente à $450 \mathrm{~km}$ da capital, Porto Alegre. De acordo com o senso de 2010 do Instituto Brasileiro de Geografia e Estatística (IBGE) a população do Município era de 49.082 habitantes.

O Município pertence à mesorregião Centro Ocidental Rio-Grandense e à microrregião de Santiago. Localiza-se, de acordo com a SEMA (2005), em partes de duas bacias hidrográficas: a Bacia do Rio Ibicuí (U-50), e a do Butuí/Piratinim/Icamaquã (U-40). Informa-se que U é indicativo de Rio Uruguai.

No que tange aos sistemas aquíferos, Santiago está, segundo o Mapa Hidrogeológico do Rio Grande do Sul de Machado e Freitas (2005), parte no Sistema Aquífero Serra Geral II (sg II) também denominado de SASG. E ainda uma parte, no Sistema Aquífero Basalto/Botucatu (bb) na Zona de Confinamento (ZC) e Zona de Aflormentos (ZA) do Sistema Aquifero Guarani constituído de uma sequência de rochas sedimentares (OEA/PEA/2009). De acordo com Silvério da Silva et al.(2004) citando Wrege (ABAS/2004) um Sistema Aquífero é definido como "o domínio contínuo, ou seja, as partes estão contidas por limites (finito) e estão ligadas hidraulicamente (dinâmico)".

O Sistema Aquífero Serra Geral II, corresponde aos sistemas que apresentam uma média a baixa possibilidade para captações de águas subterrâneas em rochas com porosidade por fraturas/fissuras. É caracterizado por ocupar a parte oeste do Estado, os limites das rochas vulcânicas como no Rio Uruguai e as litologias gonduânicas além da extensa área nordeste do planalto associada com os derrames da Unidade Hidroestratigráfica Serra Geral ou SASG. Litologicamente é composto por rochas ácidas tais como os riolitos, riodacitos e em menor proporção de rochas básicas como os basaltos fraturados. As rochas ácidas apresentam fraturas predominantemente horizontais. Informa-se que o caráter ácido e básico refere-se ao teor de 
sílica $\left(\mathrm{SiO}_{2}\right)$, no primeiro superior a $65 \%$, com quartzo, enquanto no segundo entre $52-45 \%$, sem quartzo (LEINZ e AMARAL, 1975).

O Sistema Aquífero Basalto/Botucatu pertence ao grupo de aquíferos classificados como praticamente improdutivos em rochas com porosidade intergranular ou por fraturas. Localiza-se na região da fronteira oeste e a região das missões, entre os Municipios de Unistalda e São Borja. Incluem-se também aquelas áreas com morros isolados ou testemunhos de derrames de basaltos dispostos sobre arenitos da Unidade Hidroestratigráfica Botucatu. Esta situação ocorre tanto na fronteira oeste quanto na porção leste do Estado. Em síntese, são áreas desfavoráveis ao armazenamento de água subterrânea, devido a sua condição topo-estrutural. Os poços são secos ou de baixas vazões ou produtividade especificas.

Alguns aspectos geológicos, de acordo com a CPRM (2008), Santiago aflora a Formação Serra Geral (em verde escuro e claro no mapa geológico apresentado na figura 1). A Fácies Gramado, designada k1_beta_gr, caracteriza-se por derrames basálticos granulares finos a médio, melanocráticos cinza, horizontes vesiculares preenchidos por zeolitas, carbonatos, apofilitas e saponita, apresentando uma estrutura de fluxo do tipo pahoehoe comuns, intercalações com os arenitos da Formação Botucatu. A Fácies Caxias, especificada na figura 1 como k1_alfa_cx, é caracterizada por derrames de composição intermediária a ácida, riodacitos a riolitos, mesocráticos, microgranulares a vitrofíricos, textura esferolítica comum, forte disjunção tabular no topo dos derrames e maciço na porção central, pode apresentar dobras de fluxo e autobrechas frequentes, e ainda vesículas preenchidas dominantemente por calcedônia e ágata, fonte das mineralizações da região. Estas ocorrências podem ter uma porosidade secundária devido à presença de amigdalas e vesículas.

Outra litologia presente, conforme pode ser visto na figura $1 \mathrm{com}$ legenda J3k1bt, amarelo, é a Formação Botucatu. Definida pela presença de arenito fino a grosso, de grãos arredondados e alta esfericidade, dispostos em sets ou/e cosets de estratificação cruzada de grande porte. Estes paleodepósitos são de origem eólica. 
Rev. Elet. em Gestão, Educação e Tecnologia Ambiental (e-ISSN: 2236-1170)

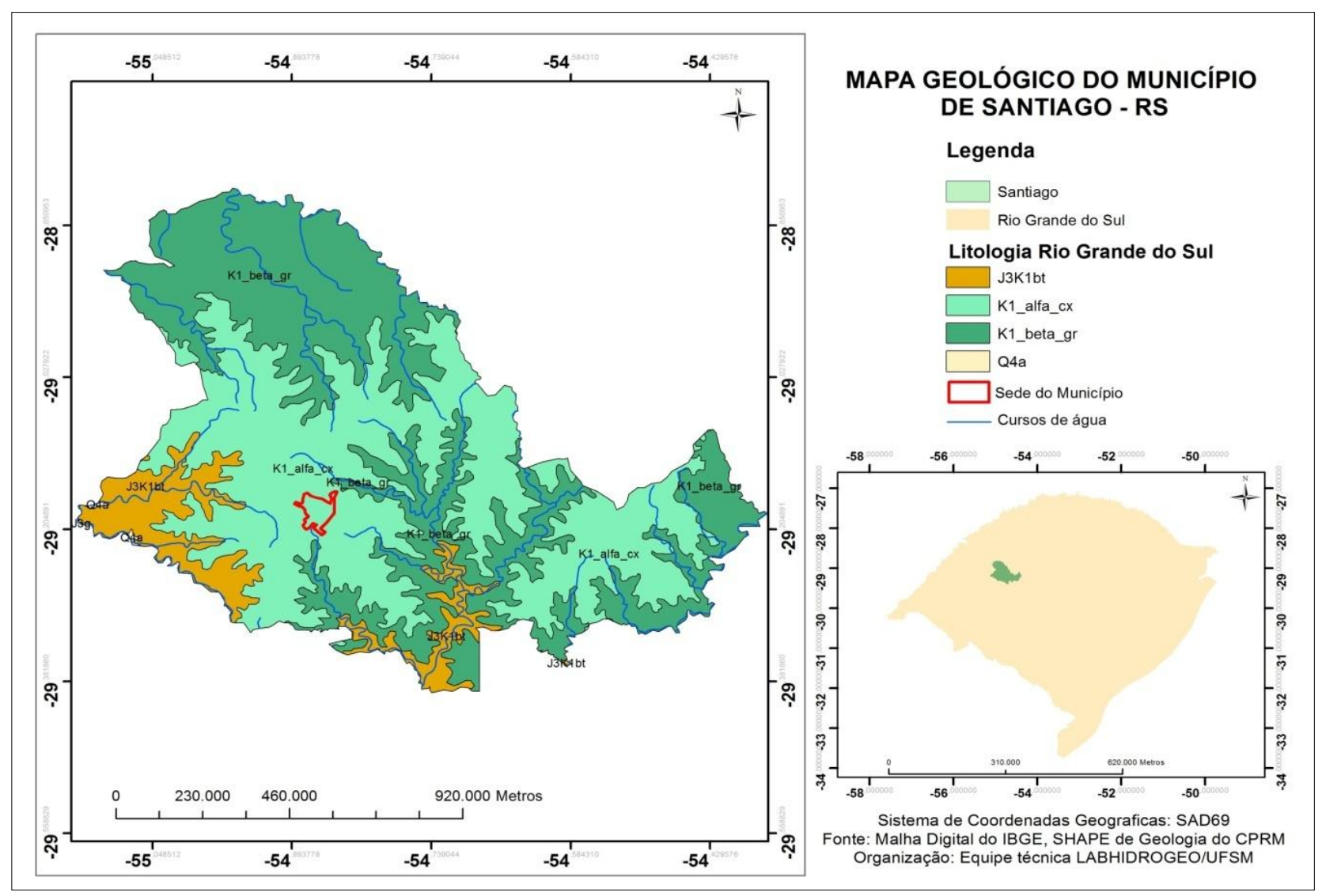

Figura 1. Mapa Geológico do município de Santiago-RS. Fonte CPRM (2008).

\section{METODOLOGIA}

Primeiramente, realizou-se a organização de um banco de dados de captações cadastradas no município (buscados no sítio da web do CPRM, Sistema de Informações de Águas Subterrâneas-SIAGAS). Dos 85 poços cadastrados, 29 foram selecionados para a pesquisa, os quais apresentavam informações completas em relação aos parâmetros avaliados e necessários para análise através do método $G O D$ de Foster et al. (2006). O método em questão caracteriza a vulnerabilidade do aquífero à contaminação o qual consiste na hierarquização de índices relativos à maior ou menor sensibilidade à poluição da zona não saturada (zona vadosa ou de aeração) (FOSTER et al. 2006). Ele consiste nas seguintes etapas:

1. Tipo de ocorrência da água subterrânea $(\mathbf{G})$, onde os valores são obtidos em um intervalo variável de 0 a 1 . Busca-se identificar a condições do meio livre, confinado, semiconfinado.

2. Classificação dos estratos acima da zona saturada do aquífero, em termos do grau de consolidação e depende do(s) tipo(s) de litologia(s) penetradas pela captação (0). Esse parâmetro é variável numa faixa de variação em um intervalo de 0,3 a 1,0.

3. Determinação da profundidade do nível da água (D), que definirá o terceiro parâmetro, no intervalo de 0,4 a 1,0. Quanto mais profundo o nível da água, menor a nota atribuída ao parâmetro. Estimando-se que será menor o risco de contaminação do meio aquífero, pois uma 
camada mais espessa ate o nível da água seria mais difícil o contaminante atingir a água subterrânea e então poder espalhar-se no meio.

Como pode ser observado na figura 2, o índice de vulnerabilidade pode ser considerado em classes padronizadas (Foster et al. 2006: insignificante $(0$ a 0,1$)$, baixa $(0,1$ a 0,3$)$, média $(0,3$ a 0,5$)$, alta $(0,5$ a 0,7$)$ e extrema $(0,7$ a 1,0$)$.

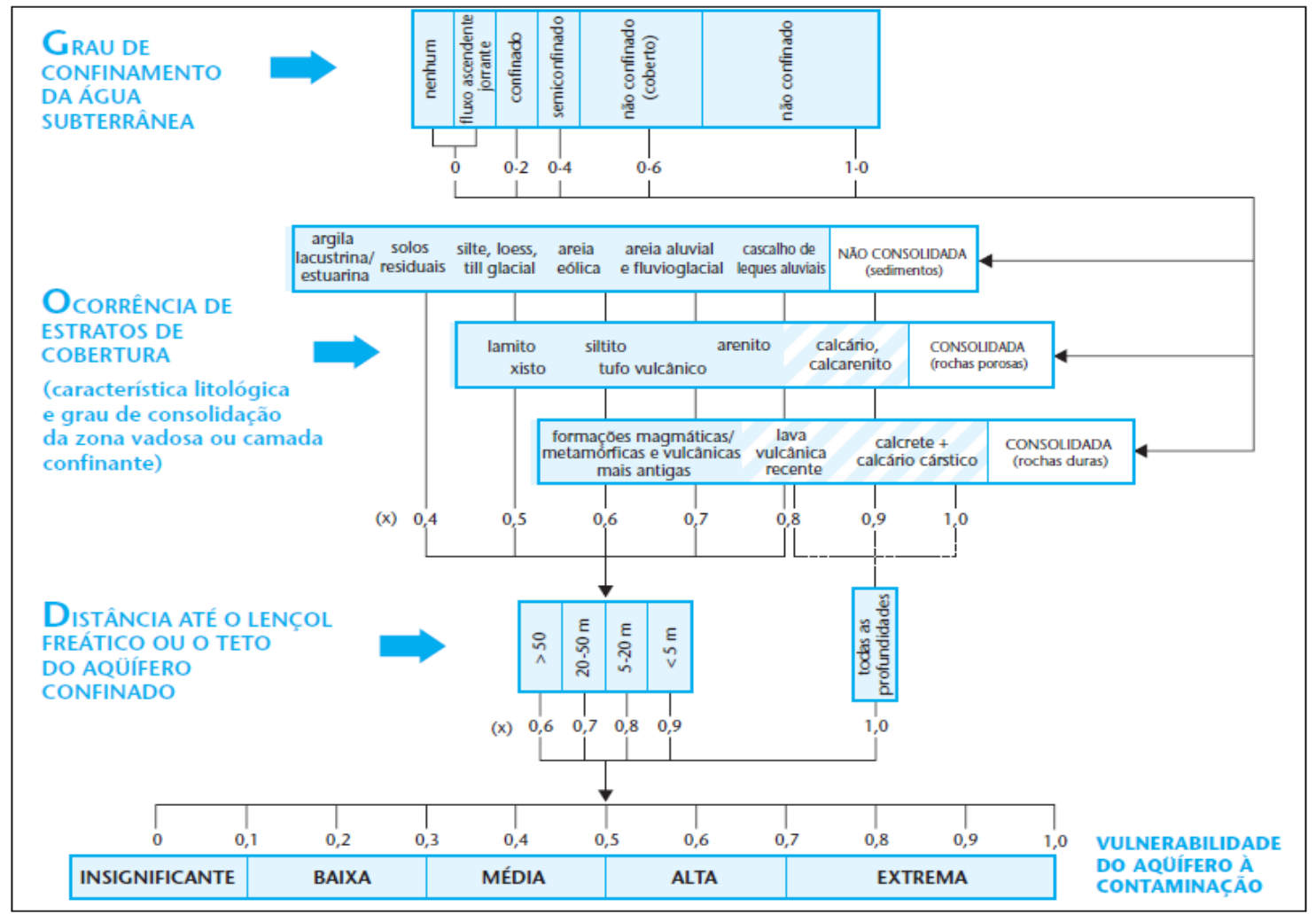

Figura 2. Sistema $G O D$ para avaliação da vulnerabilidade do aquífero à contaminação. Fonte: Foster et al.(2006).

Ao ocorrer mais de um estrato litológico no perfil geológico penetrado por determinada captação, estimou-se o percentual relativo a cada formação geológica e estimou-se seu valor no intervalo para sedimentos não consolidados, ex. areias de rios; consolidada (rocha porosa, arenitos, siltitos, argilitos) ex. SAG. E ainda inconsolidada, rochas duras, cristalinas como os riolitos, basaltos, rochas vulcânicas antigas. Depois disso, as classes são obtidas pelo produto entre os três níveis de parâmetros avaliados em cada poço considerado.

Com a utilização dos programas Surfer 8.0 e ArCGIS 9.2 obteve-se um dos produtos finais, espacializado em forma de cartograma no Sistema de Coordenadas Universal Transversa de Mercator/UTM. Assim, tornando possível a visualização das áreas de maior e menor risco à contaminação. Selecionou-se um interpolador matemático para realizar a integração dos resultados.

Em um segundo momento, foram selecionados 42 poços com dados necessários para a confecção, através dos mesmos programas, de um cartograma da superfície potenciométrica indicativo da tendência da direção de fluxo das águas subterrâneas no Município. A superfície potenciométrica foi obtida utilizando-se a relação entre a cota altimétrica na boca do poço tubular 
em relação ao nível da água subterrânea (nível estático em aquíferos livres ou teto do aquífero confinado), representando o peso da coluna de águas sobre o datum horizontal considerado, traçando-se perpendicularmente a superfície potenciométrica a direção das linhas de fluxo subterrâneo. Adotou-se como datum horizontal o South America Datum/SAD 69 e o datum vertical o Porto de Imbituba, Santa Catarina como nível médio zero do mar.

Para Heath (1983) a superfície potenciométrica é uma linha equipotencial em um mapa ou em corte vertical, ao longo da qual as cargas totais são as mesmas em relação ao datum de referencia. Para obter-se essa relação subtrai-se da cota altimétrica o nível da água retirado do SIAGAS ou quando possível medido em tubo lateral ou guia na captação Decreto Estadual no 42.047/2002 exigido para sua outorga de uso. Ela representa, portanto, uma carga hidráulica sobre um datum de referência. Com uso do programa Surfer 8.0, utilizou-se os interpoladores matemáticos indicativos das tendências dos fluxos, sendo estes vetores são traçados perpendicularmente as linhas equipotenciais.

\section{RESULTADOS}

Com as informações pré-existentes dispostas nas planilhas Microsoft Excel, e necessárias para aplicar a pontuação do Método GOD, procedeu-se à simulação de 29 poços tubulares, ilustrados na figura 3 referente a índice de vulnerabilidade e 42 captações que simularam a superfície potenciométrica, na figura 4.

Observando o cartograma (figura 3) de espacialização da vulnerabilidade natural das águas subterrâneas de Santiago, percebe-se que a classe predominante na área avaliada foi à insignificante, que apontou 22 poços, totalizando aproximadamente $76 \%$ do total avaliado. Seguida da vulnerabilidade baixa em $17 \%$ dos poços, e da média em 3,5\% das captações, Também se estimou que $3,5 \%$ dos poços avaliados apresentaram índice de vulnerabilidade alta considerando-se os sistemas aquíferos SAG e SASG. 


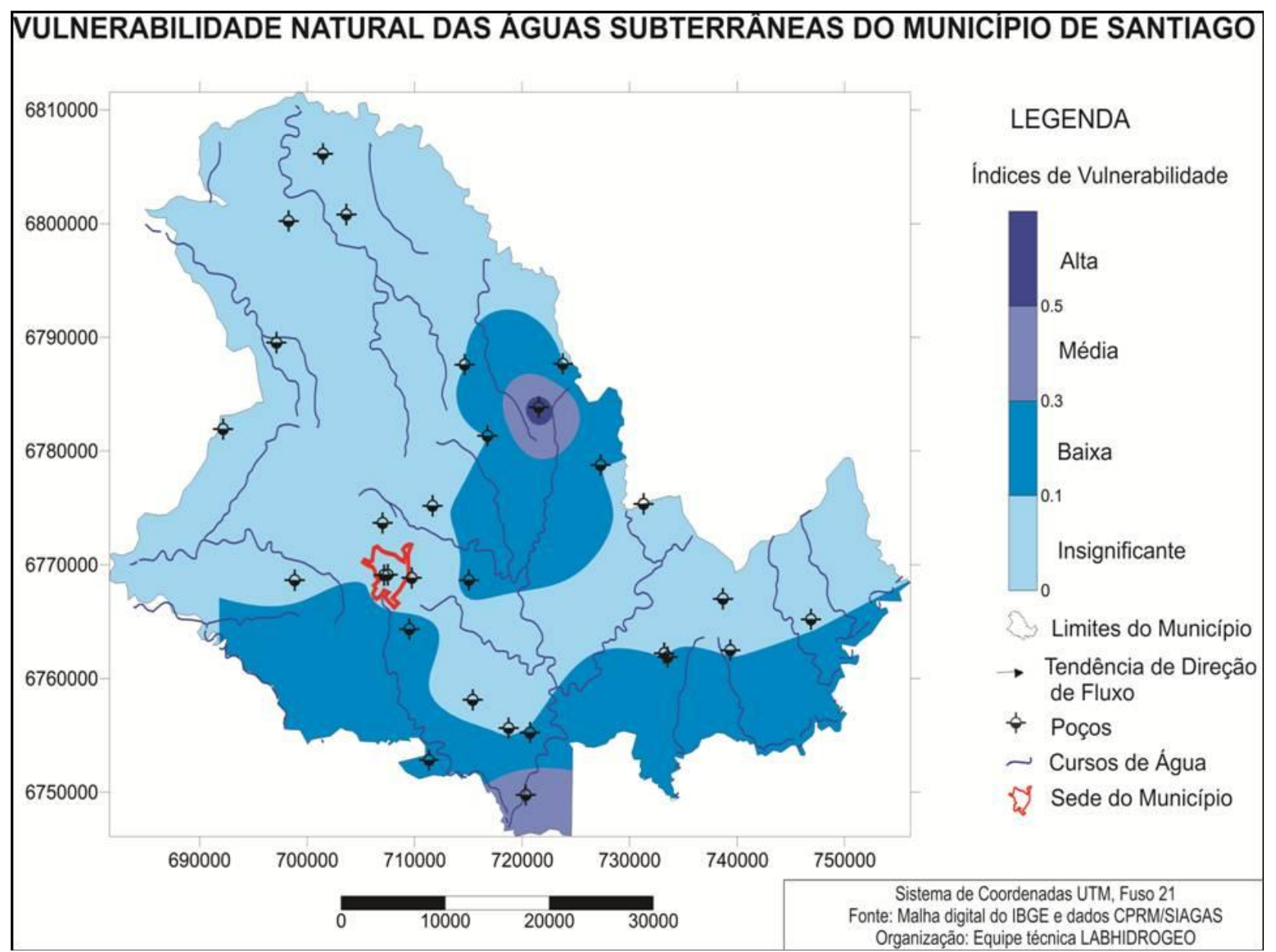

Figura 3. Cartograma da espacialização de vulnerabilidade das águas subterrâneas do município de Santiago-RS.

Na figura 4 pode-se notar que a direção do fluxo subterrâneo não apresenta predomínio de orientação, podendo estar relacionada à variação topográfica da área avaliada, mas em sua maioria se direcionam as falhas geológicas e/ou fraturas que caracterizam a região e às drenagens. Por essa tendência indicada, supõe-se que há contribuição dos sistemas aquíferos SAG e SASG na perenização dos cursos de água destas duas bacias hidrográficas.

Nota-se também, em cor de tons mais escuros, que o Município se caracteriza por possuir, em maioria, captações localizadas em um alto potenciométrico. Existem baixos potenciométricos localizados no extremo sul, e norte do cartograma, em cor amarelo claro e indicativas dos menores valores de carga hidráulica.

As estimativas de direção de fluxo das águas subterrâneas são importantes para se obtiver as tendências de direção e o sentido da pluma contaminação subterrânea provenientes de fontes como postos de combustíveis, cemitérios, lixões, esgotos in natura. Como existe grande circulação de água subterrânea, conhecendo-se o seu direcionamento, podem-se planejar ações voltadas a minimizar os riscos ou evitar a instalação de empreendimentos potencialmente poluidores em áreas com vulnerabilidade alta, extrema por exemplo. Já as tendências dos fluxos subterrâneos devem ser consideradas pelos possíveis riscos de alteração da qualidade natural nos cursos de água superficiais e/ou subterrâneos. 


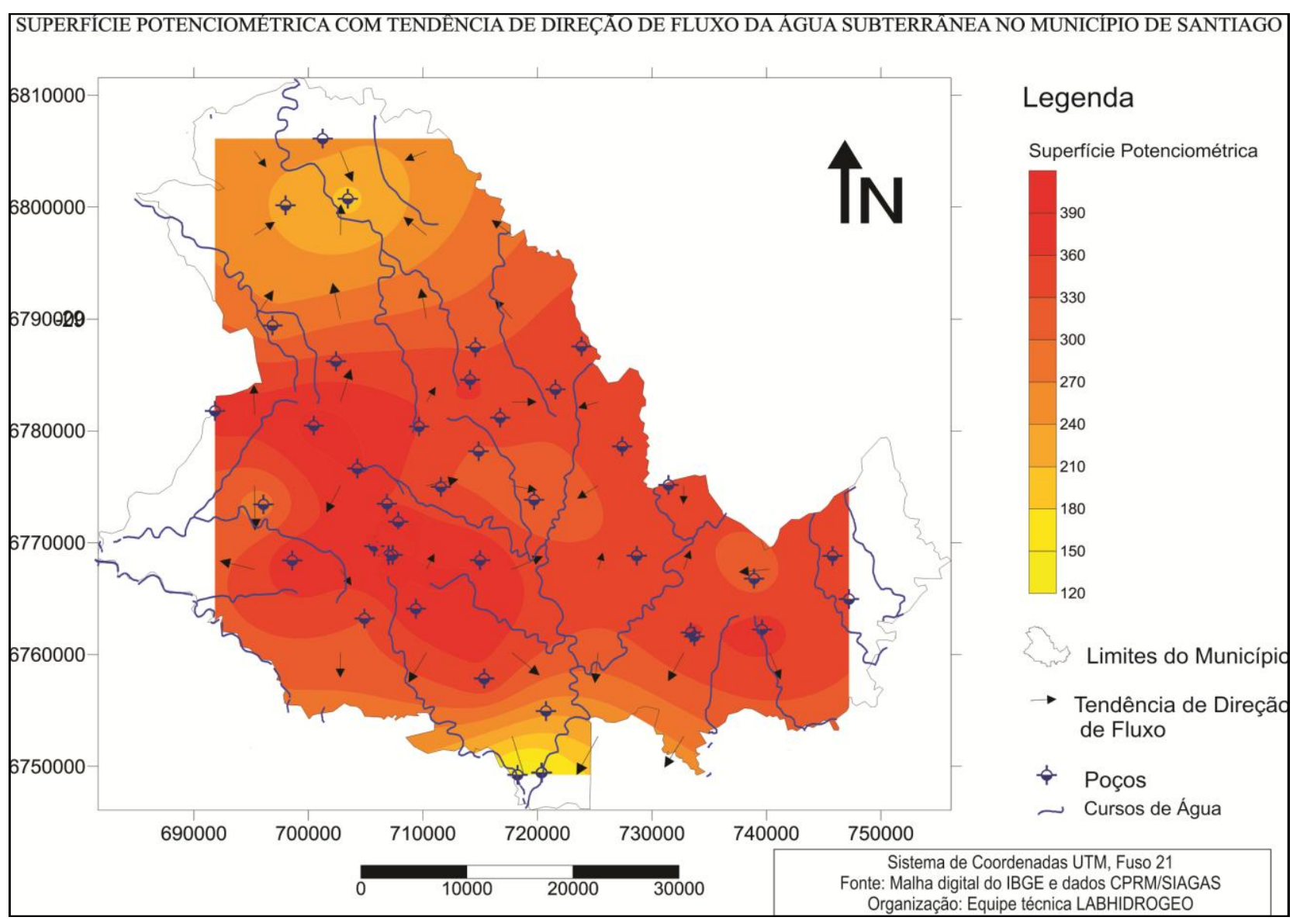

Figura 4. Superfície potenciométrica indicando astendências de direção de fluxo das águas subterrâneas do município de Santiago- RS.

\section{CONCLUSÕES}

Com base nesses resultados pode-se dizer que o município de Santiago possui a maioria das captações de águas subterrâneas localizadas em áreas de insignificante e baixa vulnerabilidade a sua contaminação. Mesmo este resultado deve ser considerado no uso e ocupação do solo, principalmente na implantação do plano diretor municipal. Ainda é necessário ter parcimônia com o licenciamento de todos os tipos possíveis de obras que utilizem o subsolo para disposição de resíduos e sua carga contaminante considerando as ocorrências de aquíferos livres e/ou confinados.

A execução do método $G O D$ é relativamente fácil quando comparada a outros métodos de avaliação de vulnerabilidade de aquíferos. Esta adaptada para as condições brasileiras.

Notou-se a formação de altos e baixos potenciométricos na área avaliada podendo estes se relacionar ao condicionamento da paisagem.

Sugere-se a aplicação de outros métodos de obtenção da vulnerabilidade de aquíferos visando à comparação de seus resultados bem como a atualização do cadastro de captações no Município. 


\section{REFERÊNCIAS}

ASSOCIAÇÃO BRASILEIRA DE NORMAS TÉCNICAS. NBR 6023. Informação e documentação: referências - elaboração. Rio de Janeiro: ABNT, 2002.

. NBR 12244. Construção de poço para captação de água subterrânea. Rio de Janeiro: ABNT, 2006.

. NBR 12212. Projeto de poço tubular para captação de água subterrânea. Rio de Janeiro: ABNT, 2006.

BORGHETTI, N. R. B; BORGHETTI, J. R.; ROSA FILHO, E. F. Aquífero Guarani: A verdadeira integração dos países do Mercosul. Curitiba: Gia, 2004.

BRASIL. CONSELHO NACIONAL DE RECURSOS HÍDRICOS. Resolução n. 15 de 11 de janeiro de 2001. Delega competência a SINGRH e dá outras providências. Diário Oficial [da] República Federativa do Brasil, poder executivo, Brasília, DF, 2001. 03p.

- Constituição (1988). Leis Constitucionais. Artigo 26. Disponível em: <http://www.senado.gov.br/legislacao/const/con1988/CON1988_05.10.1988/CON1988.pdf>. Acesso: 18 jan. 2013.

BROLLO, J. M.; VEDOVELLO, R.; ODA, G. H. Avaliação da Vulnerabilidade natural de aquíferos à contaminação através de um sistema gerenciador de informações geoambientais - Um instrumento de gestão ambiental. XXVII Congresso Interamericano de Engenharia Sanitária e Ambiental. São Paulo, 2000.

COMPANHIA DE PESQUISA DE RECURSOS MINERAIS, CPRM. Sistema de Informações de Águas Subterrâneas, SIAGAS. Banco de dados dos poços cadastrados em Santiago-RS. Disponível em: < <http://siagasweb.cprm.gov.br/layout/pesquisa_complexa.php >. Acesso em: 20 dez. 2012.

. Mapa Geológico do Estado do RS. Disponível em: < http://www.cprm.gov.br >. Acesso em: 20 dez. 2012.

FOSTER, S. S. D.; HIRATA, R. Contaminación de las águas subterráneas. Organização Mundial de laSalud. Organização Panamericana de laSalud, Centro Panamericano de Ingenieria Sanitária y Ciências Del Ambiente. Lima, Peru, 1987.

FOSTER, S. HIRATA, R.; GOMES, D.; D’ELISA, M. Proteção da Qualidade da Água Subterrânea: um guia para empresas de abastecimento de água, órgãos municipais e agências ambientais. São Paulo: Servemar, 2006.

HEATH, R. C. Hidrologia Básica de Água Subterrânea. USGS WaterSupplyPaper 2220. Traduzição Mario Wrege e Paul Potter. Porto Alegre: UFRGS/IPH, 1983.

INSTITUTO BRASILEIRO DE GEOGRAFIA E ESTATÍSTICA. IBGE - Instituto Brasileiro de Geografia e Estatística. Disponível em: <http://www.ibge.gov.br>. Acesso em: 16 jan. 2013.

LEINZ, V.; AMARAL, S. E. Geologia Geral. 6.ed. São Paulo: Companhia Editora Nacional, 1975.

MACHADO, J. L. F.; FREITAS, M. A. de. Projeto Mapa Hidrogeológico do Rio Grande do Sul: relatório final. Porto Alegre: CPRM, 2005.

MACIEL FILHO, C.; NUMMER, A. Introdução à Geologia de Engenharia. 4 ed. Santa Maria: Ed da UFSM, 2011.

OEA/PEA/PSAG- Programa Estratégico da Ação. 2009. Disponível em <http://www.mma.gov.br/ana>. Acesso em: 16 jan. 2013.

RIO GRANDE DO SUL (Estado). Constituição (1989). Constituição do Estado do Rio Grande do Sul. Porto Alegre: CORAG, 1989. 
Rev. Elet. em Gestão, Educação e Tecnologia Ambiental (e-ISSN: 2236-1170)

. Lei Estadual n. 11.520, de 03 de agosto de 2000. Institui o Código Estadual do Meio Ambiente do Estado do Rio Grande do Sul e dá outras providências. Disponível em: <http://www.mp.rs.gov.br/ambiente/legislação/id628.htm>. Acesso em 20 de janeiro de 2013.

. Decreto n. 42.047 de 26 de dezembro de 2002. Regulamenta disposições da Lei n. 10.350, de 30 de dezembro de 1994, com alterações, relativas ao gerenciamento e à conservação das águas subterrâneas e dos aquíferos no Estado do Rio Grande do Sul. Porto Alegre, dezembro 2002.

Secretaria Estadual do Meio Ambiente. Disponível em <http://www.sema.rs.gov.br>. Acesso em: 16 jan.

2013.

SHIKLOMANOV, I. A. World Water Resources - A New Appraisal and Assessment for the 21st Century. Paris: United NationsEducational, Scientificand Cultural Organization - UNESCO, 1998.

SILVÉRIO DA SILVA, J. L.; MAZIERO, L.; SANTOS, E. F. dos. Impactos da atividade humana sobre o solo - Aquíferos. In: I FÓRUM SOLOS E AMBIENTE, 2004, UFSM, Santa Maria/RS. Anais... Santa Maria: Pallotti, 2004. p. 145-167. 